\title{
LEY GENÉRICA ENTRE MUJERES Y PUTOS: DEMOCRACIA, STRONATO Y GUERRA GUASU
}

\section{Rocco Carbone *}

108/ Cuchillo de palo (España, 2010, 93 min.)

Director y Guión: Renate Costa (Paraguai)

Director de fotografia: Carlos Vásquez

Com: Renate Costa, Miguel Auad Petunia, Manuel Cuenca

Montagen: Núria Esquerra, Carlos García

Música: Berta Rojas

Productores: Jordi Ambròs, Marta Andreu, Susana Benito, Ruth Casanovas

\section{Telón. O: de las bienvenidas y los accesos}

Varias dimensiones. Paraguay es la primera. Y sobre este trabajo él formula un estado de interrogación. Lo interroga a partir de un emergente integrado por un complejo dispositivo cultural-militante, una película: 108/ Cuchillo de palo (2010) de Renate Costa. Modo de la memoria porque, desde la historia familiar, filma/reflexiona (a partir de un número que en Paraguay tiene su historia) sobre los modos homosexuales de hacer sexo en relación con la sexualidad "normal" dominante-autoritaria en la década de 1980, cuando el país aún estaba asediado por un orden político autoritario: el Stronato (1954-1989). Y al desarrollar los contenidos de la memoria de 108/ Cuchillo de palo, el trabajo descubre la existencia de una ley genérica en estado de disponibilidad a la cual el Stronato le hace producir sentido

* Universidad Nacional de General Sarmiento, Consejo Nacional de Investigaciones Científicas y Técnicas - CONICET. C1033AAJ, Buenos Aires, Argentina.

E-mail: rcarbone@ungs.edu.ar 
pero que estrictamente no le pertenece. Apenas amplía sus márgenes que, postulamos aquí, fueron articulados por lo menos 150 años antes: posguerra Guasu (1865-1870). Cuando Paraguay estaba ocupado por los ejércitos de Argentina, Brasil y Uruguay.

Estas dimensiones que entraman un diálogo permanente entre lo cultural-militante y la historia política son formuladas desde el hoy.Y que por la obviedad misma de la formulación requieren una línea de explicación: el hoy es una contemporaneidad democrática latinoamericana que nos reclama acerca de temas sensibles como los derechos humanos y las políticas de derechos humanos. Tiempos democráticos y reclamo de derechos - genéricos, concretamente - que como tales pretenden impactaren la ampliación de los marcos de ciudadanía.

\section{En casa de herrero}

En esa sub-región de América Latina que conocemos como Cono Sur suele repetirse y escucharsea menudo el refrán, "en casa de herrero, cuchillo de palo", que más o menos alude a toda persona que, siendo especialista en algún rubro, usa ese saber-hacer en cualquier lugar menos en su casa. Ésa es la parte del título menos difícil de explicar del largometraje documental (producido en España) por la cineasta paraguaya Renate Costa Perdomo y estrenado en febrero de 2010 en la Berlinale: 108/ Cuchillo de palo. La parte más compleja, y por eso mismo la que más entusiasmo provoca, sin que esta frase tenga nada de refranero, es ese numerito aparentemente inocuo: 108, que no implica ningún tipo de numerología. Ese número, precisamente, desborda lo cinematográfico-documental de Costa y lo pone en paralelo con esa porción de la historia política paraguaya que se inicia en 1954 y que "termina" en 1989. O sea, con el Stronato: régimen político-autoritario-heteropatriarcal articulado alrededor de la figura del general Alfredo Stroessner Matiauda. 
Ese numerito aparentemente inocuo hace de la película de Costa un vehículo de memoria que representa el pasado y lo incorpora fáctica y subjetivamente en el presente. Es consabido que dentro de los márgenes de la historia política paraguaya (como de los otros países del Cono Sur) la memoria fue y es dramatizada por las tensiones (irresueltas) entre recuerdo y olvido, latencia y muerte, revelación y ocultamiento, prueba y negación, sustracción y restitución. Precisamente a causa de las violentaciones (violencias más violaciones) a los derechos humanos. 108 es y tiene el sentido de un testimonio que rebate la ficción genérica pretendidamente universal del sujeto absoluto; ése que no se hurta al canon de la heterosexualidad normativa. Entonces, ese número remite a un tema de los derechos humanos, a un tema de género, pero sobre todo a uno de la democracia. ¿Por qué?

En democracia podemos recuperar esa gramática de los cuerpos articulada alrededor de las violentaciones sexuales y otros delitos de violencia de género. En democracia podemos reexplorar (reapropriar/recitar) en sus capas superpuestas la existencia de una memoria activa y disconforme. En democracia podemos recuperar sin temor las señales de vida que grafican el trauma: los hilos rojos, aún clandestinos, de ciertas memorias críticas que se rebelaron contra el determinismo ideológico de un pasado guiado por racionalizaciones finales. Las que en el Cono Sur llamamos "dictaduras".

\section{Dispositivo cul-mit}

Antes de explicitar una lectura posible del documental de Costa para ponerlo en paralelo con la historia política paraguaya, me parece relevante señalar que no se trata de un producto cultural que funciona esquizofrénicamente respecto de la realidad político-cultural que le es 
contemporánea. No se trata de un dispositivo cultural aislado de su contexto, dado que en Paraguay desde hace unos (pocos) años la cuestiónde lxs108 viene siendo abordada desde la literatura - con una novela de Armando Almada Roche,108 y un quemado. ¿Quién mató a Bernardo Aranda? (2012), un cuento de Bernardo Neri Farina, "El rock and roll de Bernardo" (2010), una dramaturgia de Agustín Núñez, 108 y un quemado (2003/2010) -, una investigación militante colectiva - ErwingAugstenSzokol y otrxs, 108/Ciento ocho (2013) - y también reivindicada por parte de grupos militantes LGTBI. Pienso en la Asociación 108 con sus múltiples acciones: la fundación de La Mansión 108 en Asunción, "un proyecto queer alternativo" (https://www.airbnb.mx/rooms/2196875), la publicación de un panfleto que ya va por su segunda edición 108/Ciento ocho (Augsten Szokol y otrxs), el blog 108 memorias (http://108memorias.com/la-historia/) o la impresión de remeras coloridas que llevan en la parte anterior el número como declaración de principios. También hay que recordar a Somos Gay (http://somosgay.org/quienes-somos), una "asociación solidaria, comprometida con la innovación de estrategias efectivas contra la homofobia". Por el lado lésbico-feminista, Aireana (http://www.aireana.org.py), espacio político cultural "de información, de encuentro (para diálogos, charlas y debates) y de servicio a mujeres lesbianas". Y Lesvos, una nueva organización de mujeres lesbianas nacida en 2013 (https://www.facebook.com/LESVOSorg/info).

108/Cuchillo de palo integra este complejo dispositivo culturalmilitante. No referir ese entramado adelgazaría el amplio debate del cual el documental de Costa participa desde las peculiaridades de su propia historia familiar - entroncada con la historia política de su país - y las del cine en tanto séptimo arte. Debate que nexa múltiples dimensiones: derechos humanos, memoria, espacios de discusión que generan relatos y acciones a propósito de la memoria y el olvido, que impulsan reflexiones que entraman justicia, memoria e historia política con el arte en un contexto pos-represión, 
de resistencia y de denuncia de la violencia, maltrato y tortura contra la homosexualidad, tanto hoy en día como durante el Stronato: un régimen político autoritario y heteropatriarcal que a lo largo de su existencia desató múltiples razzias sobre subjetividades que síse hurtaban al canon de la heterosexualidad normativa. Heterosexualidad masculina articulada alrededor del cuerpo del hombre, postulado como único sexo con existencia ontológica.

Sobre una de esas persecuciones reflexiona Renate, en un mano a mano entre ella, casi siempre detrás de cámara - como si fuera un símbolo de la memoria inquieta, indócil, escondida, que no puede parar de recordar y saber en presente sobre el pasado - y su padre - como si fuera símbolo del olvido, de lo dicho a medias, de lo negado, oculto o manoseado en el presente sobre el pasado; su padre que, como su abuelo, era (es) herrero. 108/Cuchillo de palo relata la historia de una familia o, en última instancia de dos hermanos: el viejo de Renate y su tío Rodolfo, "el cuchillo de palo", ya que contrariamente a sus hermanos y a su padre no quería ser herrero. Sino bailarín. En el Paraguay de la década de 1980. Precisión: si bien es cierto que la tensión fundamental de la película está repartida entre Renate y su padre, el documental articula otras voces/miradas que sirven para reconstruir la historia de Rodolfo. La película pone en foco a otrxs personajes, integrantes de la cultura LGTBI, que conocieron a Rodolfo de manera más o menos mediada y sus recuerdos contrabalancean la "versión familiar" paterna que Renate pretende rearticular con honor a la verdad o a otra verdad, que es la que ella pretende filmar.

Bailarín: una subjetividad reconocida visualmente como hombre, en un régimen político ya en tiempo de descuento (se narran hechos pertenecientes a la década de 1980) que se ocupó de perseguir con atención de cirujano todolo diversamente deseante en distintos ordenes del ser: ideológico, político, militante, insurgente, genérico... El Stronato, como los demás autoritarismos militares latinoamericanos, se ocupó de acotar, vigilar, 
castigar, desaparecer la circulación de signos militantes, disidentes, diversamente deseantes por medio de "medidas inmunitarias" que conocemos. La sumatoria de todos los polos victimados describían (describen) lo diversamente deseante respecto de ese Orden que opera(ba) porque sigue operando en el Paraguay de hoy - como molde disciplinario de una verdad menos revelada que obligatoria.

Rodolfo Costa: fue encontrado muerto en su domicilio, desnudo y tirado en el piso. En ese mismo momento, una Renate aúnal borde de la infancia pregunta cómo ha muerto su tío. Le replican:“de tristeza”. Un tío que ella recordaba alegre, jovial. El recuerdo de ese hecho sombrío subjetivo, familiar y en la sincronía, lo vamos a ver, colectivo - es lo que la insta a filmar muchos años después el presente para recuperar un pasado traumado y trémulo en la recuperación de su recuerdo. Filmar con vistas aformular nexos constructivos y productivos entre pasado y presente para hacer estallar el "tiempo-ahora" (Benjamin, 1989) que se ve retenido y comprimido en las partículas históricas silenciadas por las memorias oficiales.

\section{Contextuales. O: la Patria de los ortos}

Rodolfo Costa: 108. Su muerte, más precisamente, su asesinato, en la década de 1980 reactualiza(ba) el asesinato del primer 108: Bernardo Aranda, cuya muertedio inicio a la cuestión 108. Dicho esto, es el momento de explicitar qué quiere decir ese número en el ámbito del documental de Renate y en el contexto de la historia político-cultural paraguaya. Concretamente, se vincula con la primera razzia pública (ampliamente documentada por la prensa de la época y seguida por el conjunto de la sociedad) que el Stronato perpetró sobre la comunidad homosexual asuncena en 1959 y que implicó la represión de sexualidades disidentes (no obedientes a la normahetero). Una represión acontecida en setiembre de ese 
año pero que a lo largo de la experiencia stronista volvió a repetirse en otras ocasiones (con variaciones mínimas y otros sujetos, desde ya) y que creó significaciones que siguen haciendo sentido en pleno siglo XXI dentro de los márgenes de un orden pretendidamente democrático. De hecho, atendiendo a una investigación de archivo de Francisco Alcaraz Sosa, "Memoria histórica del caso 108 durante el régimen represivo del stronato", puedo hacer constar lo que sigue. Antes de 1959 y del caso de los 108, en Paraguay ya se había asociado la homosexualidad a un número: el 13. El diario La Tribuna en 1931 se ocupa de denunciar el hacinamiento de los presos en la cárcel y haciendo referencia al número de una celda, la 13, escribe: "fatídica celda donde se hospedan más de 15 recluidos, la mayor parte de ellos aficionados al vicio contra natura" (año 6, no. 2425, 7 de abril de 1931: 1). Luego de 1959, la razzia que se desató con motivo del asesinato de Aranda, volvió a repetirse con el caso de Enrique Mai, Tito Ainer, Mario Luis Palmieri y Rodolfo Costa, quien nos ocupa aquí.

Todos estos hechosmerecen ser interrogados - y en esto reside uno de los aciertos de 108/Cuchillo de palo - porque fuera del dispositivo cultural-militante que explicité anteriormente el trauma que implica la cuestión 108 aún no es motivo de reflexión ni por parte de las ciencias humanas ni de las sociales.

En 1959, Bernardo Aranda, locutor radial, fue encontrado calcinado en Radio Comuneros, su lugar de trabajo. A partir de ese asesinato, el Stronato desató una razzia y apresó a 108 presuntos homosexuales con vistas a "esclarecer" el motivo de esa muerte, cuyos móviles fueron presentados como pasionales por el poder y por el dispositivo prensa ( $E l$ País, El Independiente, Nande). A partir de ese momento se acuñó el sintagma "ciento ocho" como sinónimo despectivo para designar a todx homosexual. 
Interrogar la primera razzia o el asesinato de Rodolfo Costa en realidad busca interrogar los modos homosexuales de hacer sexo en relación con la sexualidad "normal" dominante-autoritaria impuesta por el Stronato (en este contexto de discusión, si bien esa imposición es anterior y “tan vieja como el mundo"). Modos nexados con un orden político, un orden sexogenérico, y uno anatómico de los cuerpos. También con la estabilidad de esos órdenes. En cuanto al orden: una primera base axiomática del discurso del poder autoritario-totalitario-heteropatriarcal consiste precisamente en la absolutización de un Orden como principio clasificatorio con un impacto en los discursos como en las identidades. La cuestión 108, y concretamente la de Rodolfo Costa, indica una situación de desborde respecto del sujeto monológico de la autoridad genérica propia de las tradiciones oficiales que consagraba el autoritarismo de la cultura militar. Y "ciento ocho" es una cifra que apenas tiene relevancia matemática porque su peso específico es de índole política, tal como sugerí hace unos minutos. Más concretamente, de índole sexopolítica. Y filmar sexopolíticamente, como lo hace Costa, nos permite formular una serie de reflexiones sexopolíticas de ese régimen que llamamos Stronato. Porque el sexo, el género y la sexualidad - a partir de 1959 y el asesinato de Aranda, que en la década de 1980 se reactualiza con el asesinato de Rodolfo Costa - impactaron en la actividad política y viceversa.

Mirando el documental es posible postular una relación directamente proporcional entre la lógica represiva de la patologización de la homosexualidad y el grado de opresión del régimen. En este sentido, 108 significa la activación de un mecanismo sexopolítico de orden disciplinario. Y 108 es uno de los tantos polos victimados por el Stronato que integraban una cultura contestataria cuyo objetivo general y generalizable era torcer el 
alfabeto de Tembelo. ${ }^{1}$ Polo victimado, subjetividad social traumada integrada por Rodolfo Costa y precisamente por eso su caso es menos ejemplar que colectivo - que aprendió sobre/con su propio cuerpo, un cuerpo colectivo - traumáticamente - a disputarle sentidos al habla oficial, con un sordo reclamo por más derechos y más ciudadanía, impugnando el formato reglamentario de una significación única: hombre/mujer/ heterosexual. Habla oficial con su correspondiente cultura oficial, que hablaba la lengua de la razón autoritaria. Lengua que en su propio léxico acuñó un sustantivo para designar la desviación sexual, la "degeneración" genérica, la amoralidad. Sustantivo - cuando no lengua en su totalidad - que sigue teniendo vigencia hoy en día y aparece por las calles paraguayas bajo forma de graffiti pretendidamente antifascistas.

108/Cuchillo de palo (de)muestra cómo el sistema sexo/género entró a formar parte de los cálculos del poder de manera declaradamente pública. Y cómo los 108 fueron (y son porque la racionalidad stronista es todo menos un recuerdo en Paraguay) transformados por esos cálculos, en centros moleculares de dominación heterosocial. Con el caso Costa, con las razzias del Stronato sobre la comunidad homosexual, ese orden político le agregó un apéndice a la misoginia propia de cualquier sistema heteropatriarcal: el desborde sobre la homofobia que, al fin y al cabo, ¿qué es sino una misoginia extendida?

La homofobia efectivamente es - en el sentido de que puede entenderse como - una misoginia extendida. O, dicho de otro modo, ampliando los márgenes de esta interrogación sobre la historia y la construcción de género en Paraguay, la persecución sobre el cuerpo de la homosexualidad es activable porque el orden político paraguayo entre 1954 y 1989 tenía una ley genérica en estado de disponibilidad, cuyo marco podía

\footnotetext{
${ }^{1}$ Apodo de Stroessner, basado en la palabra guaraní tembé que significa "labio", con el que se ridiculizaba su enorme papada; y tembolo, cuyo significado es persona ridícula, despreciable.
} 
ser, tal como efectivamente fue, ampliado. Una ley genérica que en 1959 casi cumplía un siglo. Una ley que por lo menos venía circulando vertiginosamente en Paraguay desde los primeros añosde la posguerra guasu. Luego de insinuar esto se precisa aquí una aparente digresión.

\section{Larga duración. O: la Patria es de los otros}

La historia política del Paraguay es un entramado tupido de hombres contrabandeados como héroes. En este sentido, resulta sintomático el Panteón Nacional de los Héroes que está en plena Asunción y enfatiza la importancia de las figuras masculinas en la historia de la patria, que es la historia patria, la patria - patría -, terreno de la historia: terreno hecho historia. Héroes: antes de Solano López y después de Bernardino Caballero, haciendo pie en Stroessner, para llegar a Cartes.A contrapelo de ese entramado, y en este contexto propongo un ejercicio de imaginación, a 150 años de una de lasmayores conflagraciones bélicas de la historia americana. Me refiero a la Guerra contra la Triple Alianza o Guerra Guasu (18651870). Que imagine la situación de Paraguay desde un punto de vista genérico sobre el fin de esa guerra y en la inmediata posguerra porque es cuando se acuña o - mejor: se refuerza - una ley de género, recuperada luego de algún modo por el orden autoritario stronista para hacerle producir sentido y perseguir el cuerpo de la homosexualidad ya sobre la mitad del siglo XX.

La patria soñada por Solano López era una patría: heterosexual, heteropatriarcal, cuya ecuación fundante es masculinidad, machismo, erección. Una verdadera patría que en Paraguay, por su historia postguerra guasu hubiera podido ser una matría. Matría opuesta a la patría: la patria oficial programada por López, ésa que descansaba sobre la guerra y la posibilidad de victoria. Y esa matría, esa Matria (Patria) que hubiera podido ser, no fue. Por qué en un país de mujeres, que habían participado en la 
guerra y que luego reconstruyeron el nuevo Paraguay, el poder siguió estando en mano de los hombres. ¿Por qué lo que venía siendo una patria no se transformó en una matria? Vuelvo a insistir sobre la razón de esta pregunta: son mujeres las subjetividades que reconstruyeron el Paraguay. O que construyeron el nuevo Paraguay.

Cuando la guerra se dio por fin por concluida con la muerte del presidente López, la población paraguaya estaba reducida a menos de 200.000 personas, lo que significó una pérdida de aproximadamente el $60 \%$ de la población existente antes del conflicto. Además, había un exceso muy marcado de población femenina con respecto a la masculina, por lo que el Paraguay fue llamado "el país de las mujeres". (Potthast, 2001: 86).

Sobre el filo de 1870 Paraguay es una nación destruida. Paraguay: país de mujeres pero no de las mujeres (distinción sutil pero decisiva). Frente a esto, la pregunta: ¿por qué en un país de mujeres, que habían participado en la guerra y que luego se encargarán de reconstruir (parir) el nuevo Paraguay, el poder siguió en mano de los hombres? ¿Por qué el Estado siguió siendo un dispositivo heteropatriarcal y masculino? ¿Por qué lo que venía siendo una patria no supo transformarse en matria? Ya que la guerra es lo que hace cambiar de sitio las cosas, reales o simbólicas que sean. Valga un punto nomás: con la guerra, la vida misma sufre una aceleración enfática que la acerca a la muerte; en el mejor de los casos. Porque en el peor la hace adherir a ella: la muerte deglute la vida transformándola en su contrario, que es ella misma.

Precisión. Matria no debe ser entendida como sinónimo de matriarcado, pues un matriarcado como mera inversión de un patriarcado sigue siendo heterosexual y opresor, con un signo inverso. Una matria, desde hoy, como construcción política, podríamos imaginarla como un orden regido por la paridad sexo-genérica. 
Posguerra Guasu la condición femenina siguió articulando una posición subalterna respecto del hombre pese a una situación novedosa: la población masculina había sido raleada sensiblemente por el conflicto bélico. Se obtura una potencialidad y la soberanía del poder, la potestas sigue siendo del paterfamilias, del dueño de casa, del señor del lugar. Esas mujeres, en situación de mayoría, son extranjeras en su propio país. Y una reflexión sobre esas mujeres implica, entre otras cosas, delimitaciones precisas entre ámbitos. Entre lo familiar y lo no familiar, entre lo extranjero y lo que extranjero no es, entre lo ciudadano y lo no ciudadano, entre lo privado y lo público, entre el derecho privado y el derecho público. Y quién puede ejercer/ocupar esas posiciones dentro del orden social. Interrogarse sobre la condición de extranjería de esas mujeres es interrogar una frontera entre lo público y lo no público, entre el acceso al poder y su negación, entre el espacio político y el lugar propio, individual o familiar, entre lo secreto y lo fenoménico. Esas mujeres se sustrajeron a la fenomenalidad pública, política, estatal. Esa frontera atraviesa una turbulencia genérico-política desestructurada con la guerra y que a partir de ese drama vuelve a reestructurarse de manera aún más potente. Las mujeres paraguayas de posguerra oponen una reacción (auto)privativa respecto del poder y por ende respecto del país (en términos de construcción política). Eso implica no fundar una matria. La ley de reconstrucción de Paraguay por parte de las mujeres sobrevivientes es paradójica: pone en colusión reconstrucción y poder.

La ecuación ahí es mujer = extranjera: como si fuera una recién llegada a Paraguay. Claro: recién llegada al Paraguay de posguerra. Ocupando un lugar-propio destruido y con el deber de reconstruirlo, pero despojada del derecho de poder/al poder: poder reivindicar poder en sí y para sí. En los márgenes de la sociedad civil y del Estado. El poder de la mujer se relega una vez más a la familia y a sus actividades complementarias: la educación, la escuela. Estamos frente a una aporía que 
emana de un conflicto: en el Paraguay posguerra Guasu hay mujeres con el poder de poder y al mismo tiempo despojadas de esa potencia. Estamos frente a una tragedia del destino: a un momento sin momento: a una posibilidad imposible. Esas mujeres sobrevivientes sitúan el poder masculino por encima del propio. Y sobre ese poder el Stronato construye sentido y poder cuando se arroga el derecho de perseguir al cuerpo colectivo de la homosexualidad. Paraguay posguerra guasues necesidad y deseo: masculinos. Un país destruido y reconstruido por mujeres. Mujeres empoderadas: con un aumento en su sensación de poder. Y sólo de sensación hablo, ya que Paraguay retoma muy rápidamente la inflexión heteropatriarcal como organizadora de la patria. Programación que no resulta extraña: la carencia otorga valor.El poder masculino, el poder del heteropatriarcado, es dictado por esas mujeres como una ley por encima de todas las demás. Y por el revés, esas mismas mujeres postulan su poder como abstracto, utópico, ilusorio. Como un poder que puede transformarse, como de hecho se transforma, en su contrario. Esas mujeres se implican en la reconstrucción y se (auto)excluyen del poder, se disocian de él en un momento histórico irrepetible, excepcional, en el que hubieran podido articular reconstrucción y poder. Postulan una ley genérica. Del deber pero no del derecho: un llamado que (auto)obliga sin exigir. Y de esa ley son responsables y víctimas, paradójicamente. Ley que de alguna manera es recogida por la Constitución de la República del Paraguay de 1870. Esa Magna Carta estuvo inspirada -principalmente- en el pensamiento liberal de la Declaración de Virginia de 1776 y en la Constitución Argentina de 1853. Con sus 118 artículos, esa norma era una formulación en contra del sistema político vigente desde 1811 y tenía un corte democrático-liberal. A partir de ese momento Paraguay es declarado república y como tal se adopta una forma de gobierno democrática representativa y el Estado se organiza en tres poderes. Se Reconoce el principio de la soberanía popular con la organización del gobierno, de acuerdo al sistema de separación de poderes 
del Estado. Por primera vez, en la historia cívica del Paraguay aparece la figura jurídica del ciudadano con derechos y deberes. Instituye también la incorporación de las libertades civiles y - en el caso de los varones mayores de edad - el sufragio. Pero no el sufragio universal. De hecho, ni mujeres ni indígenas tenían derecho al voto. En este sentido, podemos decir que esas mujeres postularon una ley genérica, de la cual fueron a la vez responsables y víctimas, recogida por la Constitución, que las pueso fuera de la ley (anomos). Posguerra Guasu, la mujer es el extranjero, el xenos, simplemente el otro absoluto, absolutamente excluido del ejercicio del poder. El poder, a partir dela posguerra, se declina en el hombre y por extensión en el sistema heteropatriarcal sin reciprocidad alguna hacia las mujeres. Sistema heteropatriarcal que puede hacer de ellas lo que se le antoje y que pude ser resumido en una palabra: rentabilidad.

Declinar esa posibilidad, de imaginar y por lo tanto construir una matria - no tanto antiheteropatriarcal como desviada de lo heteropatriarcal, las posibilidades parecen infinitas - es marcar un destino genérico para Paraguay. Que no queda relegado al post 1870 sino que impacta en las construcciones de la masculinidad y la feminidad, y en las combinaciones posibles entre esos dos paradigmas: hoy como en 1959. Esa ley genérica fija un destino: anulando el derecho de las mujeres a empoderarse (porque se declina en favor de los hombres), se lo anula también para su descendencia. Esa ley genérica de posguerra impacta así, de manera directa, en el futuro. En la posguerra se crea una dinámica, un ethos. Se condena esa patria, resultado de un momento excepcional en la historia la "tragedia" de una tierra (casi) sin hombres - a la normada existencia heteropatriarcal. Se configura una realidad de mujeres abnegadas, trabajadoras, pero sobre todo expropiadas. Del fruto de su labor por sus hijos, padres, maridos, hermanos. Madres de varones que se insertarán sin dificultades en la retahíla de abusos de género - sobre el cuerpo de la homosexualidadtambién -, de mujeres silentes, gauchitas, programadas para 
soportar penas. "Pena" que es a la vez tristeza, castigo y trabajo. ¿Hay una forma más generosa y terrible del don?

Posguerra guasu nace el Paraguay actual, un país en el cual la mujer habita en extranjería constante. En términos de poder, las mujeres paraguayas, a su pesar, se hacen cargo - en el doble sentido de que cargan con y son deudoras - del legado de Mme. Lynch (la concubina irlandesa de Solano López). Extranjeras en su país, no tanto despojadas de poder como del derecho a tenerlo. Invisibilizadas, sistemáticamente. Disminuidas. En definitiva, aún, una mayoría minorizada. Y a partir de 1959 es posible decir que esa ley genérica impacta también sobre el cuerpo de la homosexualidad. En adelante, el sistema sexo/género entra a formar parte de los cálculos del poder, del cálculo del gobierno. Y "los" 108 son transformados, por esos mismos cálculos, en centros moleculares (elementales: lo contrario de globales) de la dominación heterosocial. Además, como sugería, a la misoginia propia de un sistema heteropatriarcal se le agrega un apéndice: se desborda sobre la homofobia, que al fin y al cabo,puede entenderse como una misoginia extendida. Tanto el cuerpo femenino como el cuerpo homosexual son producto de la historia política y no simplemente de la historia natural. Misoginia y homofobia nos demuestran cómo la estructura heteropatriarcal es castradora tanto del cuerpo de la mujer como del delhomosexual (en términos simbólicos, desde ya, pero también, muy a menudo, reales: pensemos en otras geografías y en otras tradiciones como la clitoridectomía). Para el heteropatriarcado el cuerpo homosexual resulta homologable con el cuerpo de la mujer y por eso ambos pueden ser sujetos discriminados, sujetos de represión, dependencia, subalternidad. Porque en definitiva son contenidos en el mal llamado "sexo débil", respecto del único "sexo fuerte" que tiene existencia ontológica: el masculino.

\section{Marronage. O: de las salidas}


De este recorrido un tanto frenético, descienden por lo menos dos cosas. Que el cine, y dentro de ese arte 108/Cuchillo de palo, tiene el poder de crear imágenes y convertirse en un contra-laboratorio virtual de producción de realidad. Contra-laboratorio que crea las condiciones para "nuevos" recuerdos - mejor: recuerdos renovados - en nuestro presente. Y dos: que el documental de Renate Costa, junto con las obras que mencioné anteriormente en "Dispositivo cutural-militante", desde el ámbito artísticocultural, se constituyen en acciones complementarias de aquéllas de los grupos LGTBI políticamente organizados. Ese macro-conjunto de acciones/intervenciones recuperan una palabra que integra el léxico stronista y que remite a una práctica represiva - cuya ley genérica tiene sus raíces histórico-políticas posguerra guasu - pero sobre todo, se la reapropian (invertida) respecto de su uso primigenio.

En definitiva, todas esas acciones resemantizan la palabra 108 y nos devuelven en el presente un pasado revectorizado a partir del orgullo LGTBI. Y al recuperar esa palabra, recuperan también experiencias y memorias que hoy, en tiempos democráticos, si bien frágiles, reclaman derechos. Que como talespretenden impactaren la ampliación de los marcos de ciudadanía. Para un Paraguay con derechos para todos y todas y todxs. Esa re-apropiación, que tematiza 108/Cuchillo de palo, nos dona la garantía de que con la conmemoración (en tanto justicia) puede fortalecerse la democracia (en tanto verdad). Una democracia que a 150 de la Guerra Guasu no puede olvidar las peculiaridades genéricas que tiene Paraguay dentro de los entramados regionales y sobre las que impactaron las acciones de ejércitos de ocupación. 


\section{Referencias bibliográficas}

ALCARAZ SOSA, Francisco (s/data), "Memoria histórica del caso 108 durante el régimen represivo del stronato", mimeo.

ALMADA ROCHE, Armando (2010), 108 y un quemado. ¿Quién mató a Bernardo Aranda? Arandura, Asunción.

AUGSTENSZOKOL, Erwing y otrxs (2013), 108 / Ciento ocho, Arandura, Asunción.

BENJAMIN, Walter (1989), Discursos interrumpidos I. Filosofía del arte y de la historia, Taurus, Madrid.

CARBONE, Rocco (2014), Putos de fuga. Stronato, sexopolitica, trauma, memoria, Servilibro, Asunción.

DERRIDA, Jacques; DUFOURMANTELLE (1997), Anne, De l'hospitalité, Calman-Lévy, Paris.

JELIN, Elizabeth (2002), Los trabajos de la memoria, Siglo XXI, Buenos Aires.

NERI FARINA, Bernardo (2010), El siglo perdido, Servilibro, Asunción.

NUÑEZ, Agustín (2010), 108 y un quemado, Arandura, Asunción.

PRECIADO, Beatriz (2014), Testo yonqui, Paidós, Buenos Aires.

POTTHAST, Bárbara (2001), "Residentas, destinadas y otras heroínas: el nacionalismo paraguayo y el rol de las mujeres en la Guerra de la Triple Alianza". En: Potthast y Scarzanela, Eugenia (compiladoras), Las mujeres y las naciones. Problemas de inclusión y exclusión, Iberoamericana, Frankfurt/Madrid, pp. 77-92.

RICHARD, Nelly (2013), Fracturas de la memoria. Arte y pensamiento crítico, Siglo XXI, Buenos Aires.

SONDERÉGUER, María (compiladora) (2012), Género y poder. Violencias 
de género en contextos de represión política y conflictos armados, Universidad Nacional de Quilmes, Bernal.

\section{Filmografía}

108/Cuchillo de palo (2010), de Renate Costa. 